\title{
Auxiliary Head of Origin of Flexor Pollicis \\ Longus - A Case Report
}

\author{
Nagalaxmi \\ Assistant Professor, Department of Anatomy, Mandya Institute of Medical Sciences, Mandya \\ Karnataka, India. \\ E-mail: nagalaxmi.suresh21@gmail.com
}

Type of the Paper: Medical Case Study.

Type of Review: Peer Reviewed.

Indexed In: OpenAIRE

DOI: http://dx.doi.org/10.5281/zenodo.888964.

Google Scholar Citation: IJHSP

\section{How to Cite this Paper:}

Nagalaxmi. (2017). Auxiliary Head of Origin of Flexor Pollicis Longus - A Case Report. International Journal of Health Sciences and Pharmacy (IJHSP), 1(2), 19-23.

DOI: http://dx.doi.org/10.5281/zenodo.888964.

International Journal of Health Sciences and Pharmacy (IJHSP)

A Refereed International Journal

(C) With Authors.

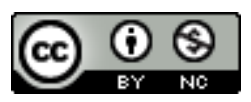

This work is licensed under a Creative Commons Attribution-Non Commercial 4.0 International License subject to proper citation to the publication source of the work.

Disclaimer: The scholarly papers as reviewed and published by the Srinivas Publications (S.P.), India are the views and opinions of their respective authors and are not the views or opinions of the SP. The SP disclaims of any harm or loss caused due to the published content to any party. 


\title{
Auxiliary Head of Origin of Flexor Pollicis Longus - A Case Report
}

\author{
Nagalaxmi \\ Assistant Professor, Department of Anatomy, Mandya Institute of Medical Sciences, Mandya \\ Karnataka, India. \\ E-mail: nagalaxmi.suresh21@gmail.com
}

\begin{abstract}
Incidence of auxiliary head of the flexor pollicis longus muscle has been described repeatedly. Accessory head has been noted arising from the lateral or more rarely from the medial border of the coronoid process of the ulna. During routine dissection, we found a rare case of an additional slip of tendinous origin of flexor pollicis longus muscle from the medial epicondyle of the humerus. However, such anomaly was not found on the left side. The embryological source and clinical impact of the current incident are discussed.
\end{abstract}

Keywords: Flexor pollicis longus, Auxiliary head, Anomaly.

\section{INTRODUCTION :}

Flexor pollicis longus (FPL) is the deep muscle of the forearm along with flexor digitorum profundus (FDP) and pronator quadratus (PQ). It takes origin from the anterior surface of the radius, and outspreads from below its tuberosity to the superior attachment of pronator quadratus. It furthermore arises from the neighbouring interosseous membrane, and habitually by a variable slip from the lateral, or medial border of the coronoid process of ulna or from the medial epicondyle of the humerus. The muscle culminates in a flattened tendon, which passes behind the flexor retinaculum and finaly attaches to the palmar surface of the base of the distal phalanx of the thumb. Flexor pollicis longus is sometimes connected to flexor digitorum superficialis, or profundus or pronator teres. The interosseous attachment, and indeed the whole muscle, may be absent. Anomalous tendon slips from the flexor pollicis longus to the flexor digitorum profundus are common [1].

The auxiliary muscles associated with the FPL and FDP is called Gantzer's muscle. Presence of Gantzer's muscle may result in variable course of median nerve or its anterior interosseous branch, hence the anterior interosseous nerve may be susceptible to entrapment by soft tissue, vascular and bony structures [2-12].

\section{CASE REPORT :}

During our routine dissection of practical anatomy course for undergraduate medical students at Mandya Institute of Medical Sciences Mandya Karnataka, India. Using conventional dissection techniques, the right upper limb of a 55 year old well-built South Indian male person with a formalin fixed cadaver is dissected with a purpose of preparation of the teaching and museum anatomical specimen. The medical history of this cadaver was not available. The skin, superficial fascia and the deep fascia were removed systematically on both sides of the flexor compartment of the forearm. We observed a rare case of additional slip of tendinous origin of flexor pollicis longus muscle on the right side. This additional slip of flexor pollicis longus was taking origin from the medial epicondyle of the humerus. On further dissection we have noticed that, from its origin the additional slip was found passing underneath the median artery and anterior interosseous nerve and joined the main muscle for its terminal insertion and measured about 6-7 cms in lenght. However, such anomaly was not found on the opposite side. Following the fine dissection, the muscle was labelled and photographed (Figure 1). 


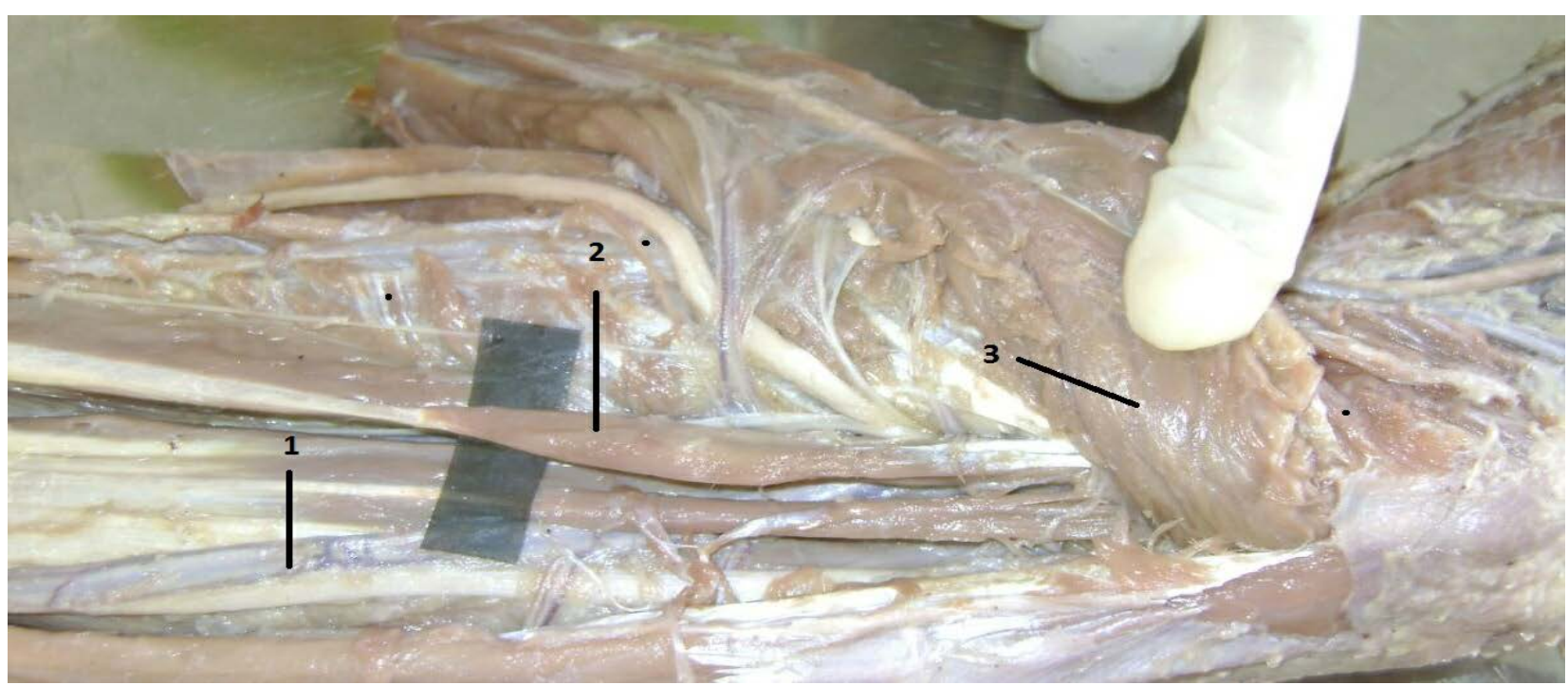

Figure 1: Photograph of the fine dissection of the muscle.

1- Flexor Pollicis Longus

2- Auxiliary Head of Flexor Pollicis Longus

3- Flexor Digitorum Superficialis

\section{DISCUSSION :}

Review of literatures shows that, the existence of auxiliary head of the flexor pollicis longus muscle has been described recurrently. Auxiliary head has been noticed that taking origin from the lateral or more rarely from the medial border of the coronoid process of ulna or also from the medial epicondyle of the humerus. Habitually, accessory head is also called as Gantzer's muscle. Although flexor pollicis longus muscle is known to present the accessory head recurrently, the incidence of its additional muscle bellies and tendons is very sporadic.

The embryological source for the presence of additional muscles in the flexor compartment of the forearm may be ascribed to the partial separation of the flexor mass. During intrauterine life, the flexor muscles of the forearm develop from the flexor mass. This mass subsequently divides into superficial and deep layers. The deep layer of the flexor muscle mass forms the flexor pollicis longus, flexor digitorum profundus and pronator quadratus. The additional muscle belly observed in the present case might have occurred due to partial cleavage of the flexor mass [13].

In the majority of instances the flexor pollicis longus receives a distinct fleshy and tendinous slip springing, in common with the flexor digitorum superficialis, from the coronoid process of ulna or medial epicondyle of humerus, or from both. The fleshy fibres of flexor pollicis longus are inserted on a tendon which appears along the ulnar border of the muscle, close to the index tendon of the deep flexor of the fingers [14]. The flexor pollicis longus muscle may be fused with the flexor digitorum profundus, the flexor digitorum superficialis, or with the pronator teres. It may be incompletely replicated, giving rise to an accessory tendon that extends to the index finger. The origin may extend to the medial epicondyle of the humerus [15]. Fleshy slips are sometimes present uniting the belly of flexor pollicis longus with flexor digitorum superficialis or profundus. These, as well as humeral and coronoid heads, are indications of the original connection between the divisions of the deep flexor sheet of muscles. The accessory coronoid head is subject to some variation, occasionally being divided distally into two or three slips passing to flexor pollicics longus (FPL), flexor digitorum profundus (FDP), flexor digitorum superficialis (FDS) or pronator teres (PT). Flexor pollicis longus may arise from brachialis [16].

Occurrence of unusual heads of origin of flexor pollicis longus may effect in variable course of anterior interosseous nerve, hence the anterior interosseous nerve may be vulnerable to entrapment by soft tissue, vascular and bony structures. Palsy of the 
anterior interosseous nerve has been described in association with neuralgic amyotrophy, isolated neuritis and entrapment neuropathy. Repetitive trauma to the forearm and structural anomalies cause anterior interosseous nerve syndrome. Hence it would be reasonable that anterior interosseous nerve passing posteriorly or laterally to the supplementary head of flexor pollicis longus muscle would be more likely to be accompanying with anterior interosseous nerve syndrome due to anatomic considerations [17].

\section{CONCLUSION :}

Awareness of anomalous tendinous origin of the flexor pollicis longus reported in the present case is essentially important to avoid any clinical complications during routine forearm surgery. The current study also enhances the knowledge on the auxiliary muscle and its relationship with the anterior interosseus nerve, which may be the contributing cause for the complete anterior interosseous nerve syndrome.

\section{REFERENCES :}

[1] Standring, S.; Berkovitz, B. K. B.; Hackney, C. M.; Ruskell, I. G. L. Gray's Anatomy. The Anatomical Basis of clinical practice. 39th Churchill \& Livingstone, Edinburg, 2005; p. 877-878.

[2] Campos D, Nazer MB, Bartholdy LM. Anatomical variation of the accessory muscle of forearm (Gantzer's muscles) and his relationship with the median nerve: a case report in human. Braz J Morphol Sci 2009; 26:39-41.

[3] Pai M.M., Nayak S.R., Krishnamurthy A, Vadgaonkar R, Prabhu L.V., Ranade A.V. et al. The accessory heads of flexor pollicis longus and flexor digitorum profundus: Incidence and morphology. Clin Anat 2008; 21:252-58.

[4] Potu BK, Gorantla VR, Pulakunta T, Rao MS, Mamatha T, Vollala VR et al. Accessory head of flexor pollicis longus muscle and its significance in anterior interosseous nerve syndrome: case report and review. Int J Morphol 2007; 25:91114.

[5] Mahakkanukrauh P, Surin P, Ongkana N, Sethadavit M, Vaidhayakarn P.
Prevalence of accessory head of flexor pollicis longus muscle and its relation to anterior interosseous nerve in Thai population. Clin Anat 2004; 17:631-635.

[6] Narayana K., Narendiran K., Shetty K.P., Prashanthi N. A case of coexistence of three anatomical variations in the forearm: Gantzer's muscles, MartinGruber anastomosis, and nerve of Henle. Eur J Anat 2004; 8: 81-84.

[7] Oh CS, Chung I.H, Koh K.S. Anatomical study of the accessory head of the flexor pollicis longus and the anterior interosseous nerve in Asians.Clin Anat 2000; 13:434-38.

[8] Jones M, Abrahams P.H., Sañudo J.R., Campillo $\mathrm{M}$. Incidence and morphology of accessory heads of flexor pollicis longus and flexor digitorum profundus (Gantzer's muscles). J Anat 1997;191:451-55.

[9] Bilecenoglu B, Uz A, Karalezli N. 2005. Possible anatomic structures causing entrapment neuropathies of the median nerve: An anatomicstudy. Acta Orthop Belg 71:169-176.

[10] Eid N and Otsuki Y. A case of double Gantzer's muscle and its possible role in nerve entrapment. Clin Anat 2009; 22:881-82.

[11] Degreef I, De Smet L. Anterior interosseous nerve paralysis due to the Gantzer's muscle. Acta Orthop Belg 2004;70:482-84.

[12] Kaplan E, Spinner M. The anterior interosseous nerve syndrome. $\mathrm{J}$ Bone Joint Surg 1969 ; 51-A:1677-85.

[13] Swamy Shantakumar R, Rao Sirasanagandla S, Badagabettu Nayak S, Rao Kappettu Gadahad M, Nagabhushan Somayaji S and Kumar N. Multiple tendons of the additional belly of flexor pollicis longus in the carpal tunnel: Embryological perspective and their clinical significance. Forensic Medicine and Anatomy Research. 2013; 1(4), 7073.

[14] Schafer ES, Symington J, Bryce T.H. Quain's Element of Anatomy; Myology, 
Volume IV, Part II. London, Longmans, Green, and Co. 1923; p.136.

[15] Anson B.J.. Morris’ human anatomy. 12th Ed., New York, Mc Graw-Hill Book Company. 1966; p. 506.

[16] Bergman R.A., Thomson SA, Afifi A.K., Saadeh F.A. Compendium of Human Anatomic Variation. Baltimore, Urban \& Schwarzenberg. 1988; p. 14.

[17] Shanmuga Sundaram Mani, Vishnumaya G, Madhan Kumar SJ. Accessory head of flexor pollicis longus and its significance in anterior interosseous nerve neuropathies and precision handling. International Journal of Anatomical Variation. 2010; 3, 46-48. 